\title{
The trilemma of designing international bioethics curricula
}

\author{
Bert Gordijn ${ }^{1} \cdot$ Henk ten Have ${ }^{2}$
}

Published online: 20 December 2017

๑) Springer Science+Business Media B.V., part of Springer Nature 2017

Cultural diversity is certainly one of the challenges one faces when designing curricula for international bioethics students. Piasecki et al. contend "[...] it is very difficult if not impossible to create an ethnically and culturally neutral message, but what really matters is not the message itself, but the forum: where critical ideas and reflections are discussed by the students. The values [...] should be clearly declared, but there should be space to contest them" (Piasecki et al. 2018, this issue). We certainly agree with both the importance of transparency of the values inherent in a teaching program as well as the idea of allowing critical discussion of said values. However, as to 'the message itself', i.e. the content of bioethics curricula, however, we claim that it is imperative as well. In fact, when designing a bioethics curriculum with the aim to teach it in international settings, you face the following trilemma. Either you develop a curriculum with the intention to promote some normative ethical theory or you do it without that objective. If you do endorse a normative theory within your curriculum, it will either be moral relativism or some universal ethical theory. All three options involve their own specific problems.

\section{Curricula not promoting any specific normative theory}

If you develop a curriculum that is not based on any specific normative theory, your teaching program might of course involve metaethics: you could focus on the Frege-Geach problem, go into the specifics of deontic logic, touch on the question of whether ethical claims are eligible for assessments in terms of truth, and the like. You might likewise engage in descriptive ethics and, for instance, present an

Bert Gordijn

bert.gordijn@dcu.ie

1 Institute of Ethics, Dublin City University, Dublin, Ireland

2 Center for Healthcare Ethics, Duquesne University, Pittsburgh, USA overview of distinctive moral attitudes in different cultures or historic epochs. Additionally, you could discuss a selection of normative ethical theories, analyze them, point out problematic premises, identify internal contradictions, and so on. However, in doing all of the above, you will refrain from any engagement with ethical theories or normative attitudes on a normative level. After all, you are not teaching from any specific normative theoretical background. Accordingly, your curriculum will fail to contribute to the development and dissemination of a uniform normative framework for the assessment of international and transcultural institutions, practices and actions.

\section{Curricula promoting moral relativism}

If your teaching programme is based on and meant to promote moral relativism, it will endorse the idea that ethical issues within a particular local culture should be dealt with by using the normative standards engendered within and endorsed by that specific culture. This view will therefore confirm the moral status quo in local cultures and thus block any criticism from outside based on normative standards that are not part and parcel of the homegrown culture at hand. The normative ethical theory that such a teaching programme promotes, i.e. moral relativism, will not be able to deal effectively with international issues that transgress boundaries of local cultures, such as human trafficking, climate change, pandemics, brain drain of healthcare workers, organ trade, and the like. After all, it remains unclear what ethical standards to use when assessing phenomena that transgress the boundaries of local cultures, i.e. the most urgent issues of global bioethics today. Besides, moral relativism seems to promote a universal norm of tolerance and respect for the other cultures, which leads to contradictions when a specific culture explicitly repudiates this norm. Should in such a case the denial be respected or tolerated? In addition, the concept of culture is inherently imprecise, which leads to confusion when it comes to identifying 
specific cultures and their distinctive normative frameworks that ought to be respected.

\section{Curricula promoting a universal normative theory}

In 1947 the Executive Board of the American Anthropological Association published a Statement on Human Rights, which involves a moral relativist critical stance on the endeavour to develop a Universal Declaration of Human Rights (Executive Board, 1947). In this statement, the authors stress the importance of respect for cultural diversity, which they argue, "[...] is validated by the scientific fact that no technique of qualitatively evaluating cultures has been discovered" (Executive Board 1947, p. 542). Furthermore, they maintain that ethical norms " [...] are relative to the culture from which they derive so that any attempt to formulate postulates that grow out of the beliefs or moral codes of one culture must to that extent detract from the applicability of any Declaration of Human Rights to mankind as a whole" (Executive Board, 1947, p. 542). Ever since, any attempt to launch universal ethics declarations or develop teaching programmes promoting universal ethical theories has been likely to spark critical reactions inspired by moral relativist ideas. So, if your teaching program is based on and intended to promote a specific universal normative theory, your curriculum might contribute to the development and dissemination of a uniform global bioethics framework for the normative appraisal of international and transcultural ethical matters. However, on the flipside, you will have to face relativist criticism and, possibly, accusations of cultural imperialism.

\section{References}

Piasecki, J., K. Dirksen, and H. Inbadas. 2017. Erasmus Mundus Master of Bioethics: a case for an effective model for international bioethics education. Medicine, Health Care and Philosophy https:// doi.org/10.1007/s11019-017-9814-x.

The Executive Board, American Anthropological Association. 1947. Statement on human rights. American Anthropologist, 49 (4): 539-543. 